\title{
Oral zinc supplements in non-responsive coeliac syndrome: effect on jejunal morphology, enterocyte production, and brush border disaccharidase activities
}

\author{
P E JONES* AND T J PETERS. \\ From the Department of Medicine, Royal Postgraduate Medical School, London
}

SUMMARY Three patients with clinically mild non-responsive adult coeliac syndrome were treated for eight weeks with oral zinc sulphate, and detailed biochemical and morphological studies were performed on the jejunal mucosa before and on treatment. Plasma zinc levels were reduced before treatment and rose to normal levels with therapy; mucosal zinc was normal before treatment and increased after therapy. Oral zinc supplementation did not alter the villous morphology, intraepithelial lymphocyte count or in vitro enterocyte production rate. In addition, there was no improvement in the clinical status of the patients. There was, however, a small increase in the activity of certain of the brush border disaccharidases. This effect may be due to direct stabilisation of the brush border membrane. The clinical value of zinc supplements in coeliac syndrome remains to be determined.

In patients with typical coeliac syndrome gluten withdrawal results both in improved absorption of dietary nutrients and in regeneration of the villi of the jejunal mucosa. Non-responsive coeliac syndrome is a related disorder in which there is malabsorption and a flat jejunal mucosa with failure to regenerate villi after careful and prolonged gluten withdrawal. It has been estimated that this group of patients comprises between 10 and $20 \%$ of adult coeliacs and, in some, the malabsorption may be severe enough to cause death. ${ }^{1}$

We have previously shown that in non-responsive coeliac syndrome, in contrast with gluten-sensitive enteropathy, there is a reduced rate of in vitro enterocyte production ${ }^{2}$ and differences in the activities of endoplasmic reticulum and brush border enzymes of the enterocytes. ${ }^{3}$ Love and co-workers reported low serum zinc levels in six severely ill nonresponsive coeliacs and obtained a clinical response after zinc supplementation. ${ }^{45}$ The aim of the present study was to determine the extent of tissue zinc

-Present address: University Department of Gastroenterology, Manchester Royal Infirmary, Oxford Road, Manchester, M13 9WL.

†Address for correspondence and present address: Division of Clinical Cell Biology, MRC Clinical Research Centre, Watford Road, Harrow, Middlesex, HA1 3UJ.

Received for publication 30 October 1980 deficiency in three patients with non-responsive coeliac syndrome and to determine the effect of oral zinc supplementation on clinical status, jejunal morphology, in vitro enterocyte production, and the activities of brush border maltase, sucrase, and lactase.

\section{Methods}

\section{Patients}

Three patients with clinically mild non-responsive coeliac syndrome were studied (Table). Nonresponsive coeliac syndrome is defined as a condition with idiopathic subtotal villus atrophy and malabsorption in patients who show no morphological response to at least five years of a strict gluten free diet. All patients had malabsorption of at least two dietary nutrients and a persistently flat jejunal mucosa despite strict and prolonged gluten withdrawal confirmed both by dietary history and normal serum anti-gliadin antibody titres. The patients were clinically only mildly affected and had not received corticosteroids before the present study. Subsequently they received a course of prednisolone, $20 \mathrm{mg}$ daily, after which all patients showed a significant clinical improvement with a marked increase in intestinal function and morphological appearance. 
Table Clinical details of patients with non-responsive coeliac syndrome

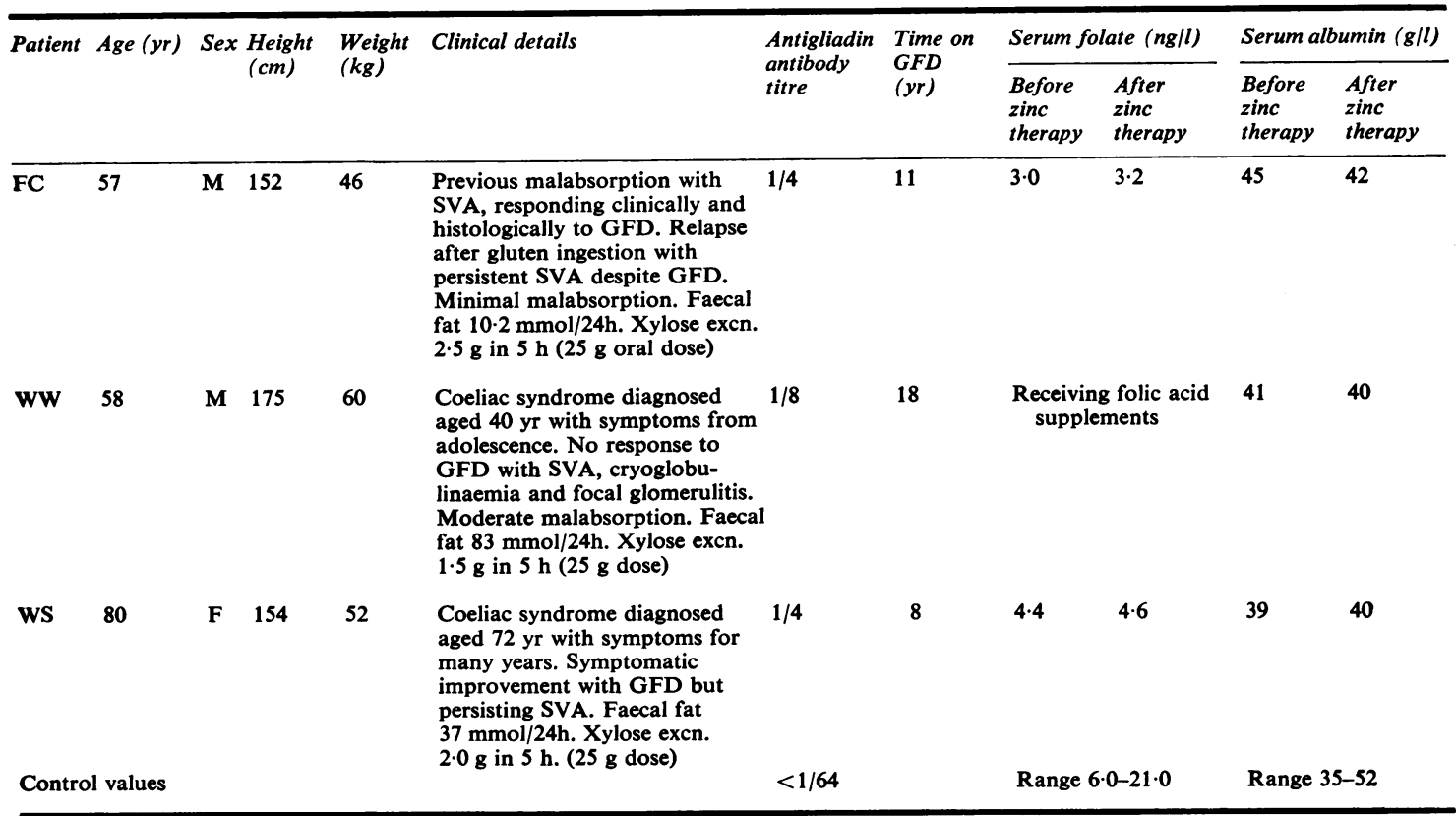

GFD: gluten-free diet. SVA: subtotal villous atrophy.

Jejunal biopsies were obtained from each patient in the usual manner, $10 \mathrm{~cm}$ distal to the ligament of Treitz, with a Watson-Crosby capsule. Biopsies were divided into pieces for: (1) routine histology, measurement of surface:volume ratio ${ }^{6}$ and intraepithelial lymphocyte counting ${ }^{7}$; (2) measurement of zinc concentration; (3) determination of in vitro enterocyte production ${ }^{2}$; (4) assay of maltase, sucrase, and lactase activities. ${ }^{8}$ Each patient continued on a gluten free diet and, in addition, received zinc sulphate capsules $220 \mathrm{mg}$ three times daily for a period of eight weeks. At the end of this period samples of blood, 24 hour urine, and jejunal biopsies were collected and re-assayed.

Zinc was assayed spectrophotometrically using a Perkin Elmer atomic absorption spectrophotometer, model $360 .^{\circ}$ Members of the laboratory and medical staff served as controls for plasma and urine zinc. Three patients undergoing investigation for gastrointestinal symptoms with normal jejunal morphology served as controls for measurement of surface: volume ratios. Student's paired $t$ test was used for statistical analysis. The study was approved by the local ethical committee.

\section{Results}

Plasma zinc (Fig. 1) was low in all three patients, in two (WS and WW) levels were more than two standard deviations below the mean control value. After treatment plasma zinc rose in all three patients to control values and this was statistically significant $(P<0.01)$. Twenty-four hour urine zinc did not differ from controls but rose after treatment; this rise was marked in only one patient (FC). Jejunal zinc concentration also did not differ from controls but rose in each patient after treatment; the increase was particularly marked in the same patient (FC). In none of the three patients did the period of zinc treatment result in any significant change in body weight, frequency of bowel action, haemoglobin level, plasma albumin, or serum folate.

Histological examination of the jejunal biopsies before and after treatment showed flat mucosa. Surface:volume ratios (Fig. 2) were below the control range and there was no change after zinc treatment. Intraepithelial lymphocyte counts in biopsies from the three patients were 12-36/100 epithelial cells before treatment and showed no significant change after treatment with values of 13-25/100 epithelial cells. Enterocyte production in vitro by jejunal mucosa (Fig. 3) did not differ from controls and did not show the increased rate characteristic of untreated gluten-responsive coeliac mucosa. After treatment with zinc there was a small, but not statistically significant, fall in in vitro enterocyte production.

Jejunal maltase activity (Fig. 4) in the three 


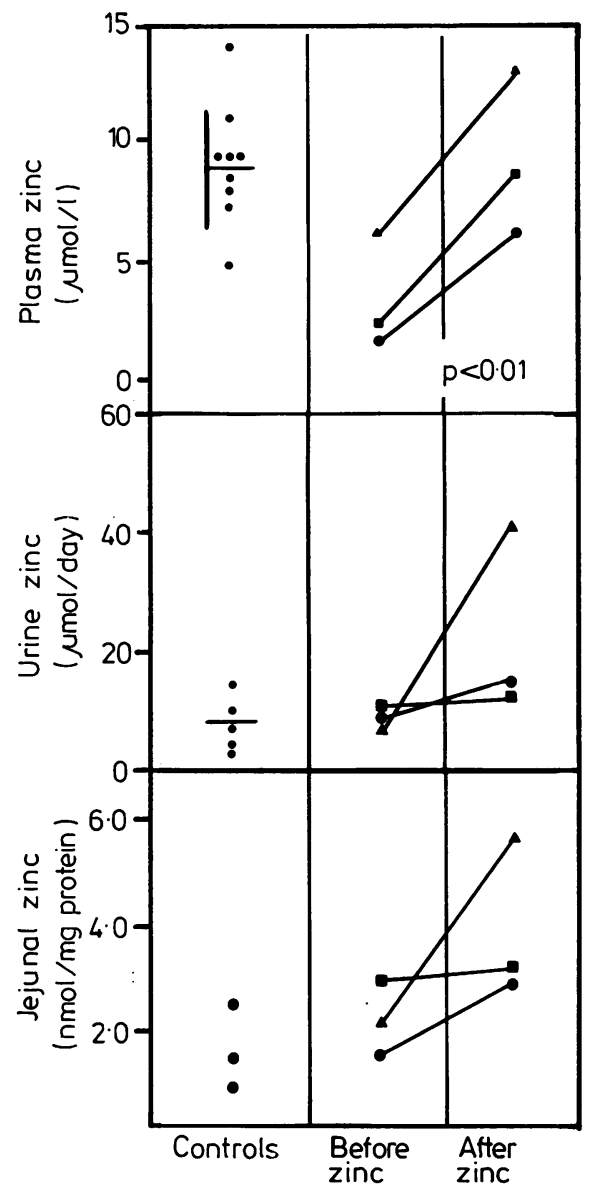

Fig. 1 Plasma, urine, and jejunal zinc concentrations in control subjects and patients with non-responsive coeliac syndrome. Plasma zinc levels $\pm S D$. Patients: $\triangle-\triangle$, $F C ; \square-\square, W W ; \bigcirc, W S$.

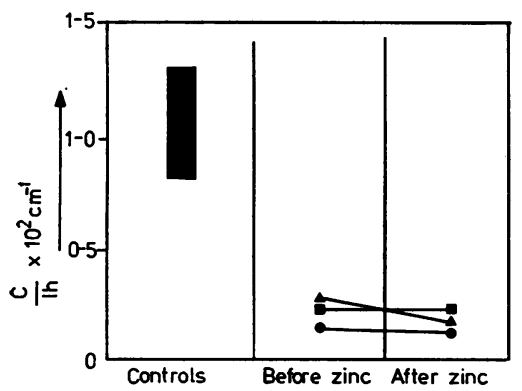

Fig. 2 Jejunal morphology in control subjects and patients with non-responsive coeliac syndrome. Symbols as in Fig. 1.

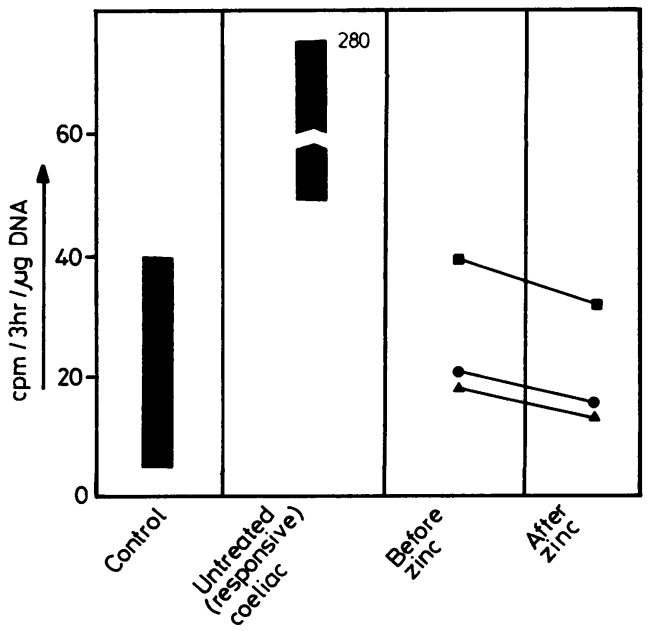

Fig. 3 In vitro jejunal enterocyte production rate in control subjects and patients with responsive or nonresponsive coeliac syndrome. Symbols as in Fig. 1.

patients was low compared both with control and with untreated responsive coeliac mucosa. After zinc treatment maltase activity increased in all three patients. Jejunal sucrase activity was lower than control values and in two patients (FC and WS) lower than usually found in untreated responsive coeliac syndrome. After zinc treatment jejunal sucrase activity increased in two patients (FC and WW) and did not change in one (WS). Jejunal lactase activity (Fig. 4) was low in all three patients compared with untreated responsive coeliac mucosa. After treatment, lactase activity increased in one patient (FC) and did not change in the other two. The patient (FC) who showed the largest net increase in zinc content of plasma, 24 hour urine, and jejunal tissue also showed the greatest increase in jejunal maltase, sucrase, and lactase activities.

\section{Discussion}

The treatment of non-responsive coeliac syndrome is at present unsatisfactory; while some patients are able to maintain reasonable health on a gluten free diet with vitamin supplements, most have symptoms of moderate to severe malabsorption and in some this may be fatal. ${ }^{1}$ The need, therefore, for a better understanding of the processes involved ${ }^{3}$ and for more effective therapy is important.

In our three patients pretreatment plasma zinc levels were low and showed a significant increase after zinc treatment. Plasma zinc is bound approximately $60 \%$ to albumin and $30 \%$ to $\alpha_{2}$-globulin. ${ }^{10}$ The low levels of plasma zinc are therefore not due 


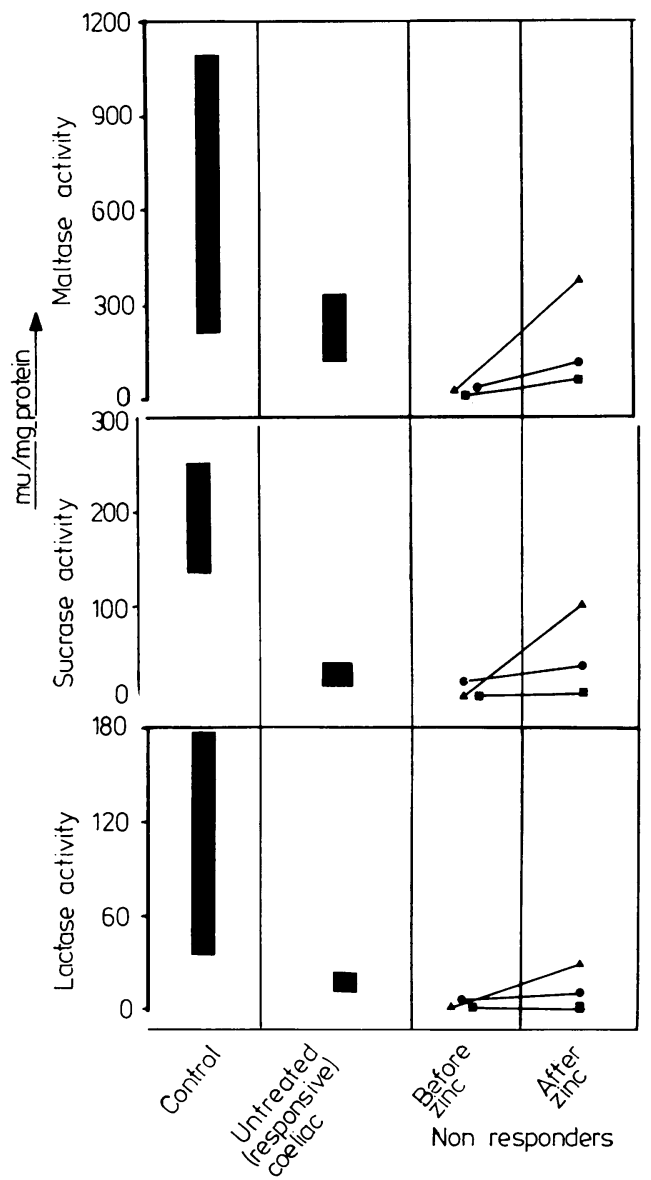

Fig. 4 Jejunal disaccharidase activities in control subjects and patients with responsive or non-responsive coeliac syndrome. Symbols as in Fig. 1.

to an alteration in the plasma albumin level. Low levels of plasma zinc are also found in untreated gluten-responsive coeliac syndrome. ${ }^{112}$ However, plasma zinc in one group of non-responsive coeliac patients has been found to be lower than in a group of untreated gluten-responsive patients and this also cannot be explained on lower serum albumin levels alone. ${ }^{5}$ Plasma zinc concentrations are, however, a poor measure of total body zinc stores ${ }^{13}$ and the normal level of jejunal zinc suggests that our patients may not be zinc deficient at the cellular level. The rise in plasma zinc in the three non-responders indicates that they were able to absorb significant quantities of oral zinc sulphate and it is of interest that the patient with the highest plasma zinc before and after treatment (FC) showed the greatest increase in urinary zinc. Jejunal zinc concentration in the three patients rose after zinc supplementation.
However, zinc content of leucocytes and connective tissue will contribute to the total zinc concentration in the jejunal biopsy homogenate, so that the values measured do not necessarily indicate enteroblast or enterocyte zinc content.

In none of the three patients was there a significant change in the clinical status after the period of zinc treatment. The differences between the response in the patients we have studied and that of the Belfast patients ${ }^{5}$ is probably because the latter group of patients were severely ill with more marked malabsorption.

Zinc treatment resulted in no subjective improvement in jejunal morphology. The failure to regenerate villi in non-responsive coeliac syndrome is associated with and probably due to a reduction in enteroblast mitotic rate. ${ }^{2}$ Zinc is essential for RNA dependent DNA polymerase activity, ${ }^{14}$ so that it is reasonable to consider whether zinc deficiency might result in a reduced rate of DNA synthesis in man. Our studies, however, indicate that zinc deficiency alone is not responsible for the reduced rate of enteroblast division and enterocyte production in non-responsive coeliac syndrome.

Zinc supplementation did result in an increase in the activities of jejunal brush border disaccharidases and this may conceivably lead to improved digestive and absorptive function of the enterocyte. The mechanism of the increase in brush border disaccharidase activity is uncertain. Certain brush border enzymes are activated in vitro by $\mathrm{Zn}^{2+}$ ions ${ }^{15}{ }^{16}$ or are themselves zinc-protein complexes. ${ }^{17} \mathrm{~A}$ more likely explanation of the beneficial effect is that $\mathrm{Zn}^{2+}$ ions act as membrane stabilisers ${ }^{18}{ }^{19}$ inhibiting the degradation of the brush border enzymes.

From the clinical response obtained in the Belfast group of patients and the improvement in brush border enzyme activities that we have found, a trial of oral or intravenous zinc supplements might be of value in this syndrome, particularly in those patients who have failed to show a response to gluten withdrawal and systemic corticosteroids.

The zinc estimations were performed by Ms C Seldon. We thank Dr C C Booth for his encouragement and Mrs D Gregory for secretarial assistance. This work was financed by the Medical Research Council and The Grocers' Trust.

\section{References}

${ }^{1}$ Booth CC. The enterocyte in coeliac disease. $\mathrm{Br} \mathrm{Med} \mathrm{J}$ 1970; 3: 725-31.

${ }^{2}$ Jones PE, Peters TJ. DNA synthesis by jejunal mucosa in responsive and non-responsive coeliac disease. $\mathrm{Br}$ Med J 1977; 1: 1130-1. 
${ }^{3}$ Peters TJ, Jones PE, Jenkins WJ, Wells G. Analytical subcellular fractionation of jejunal biopsy specimens: enzyme activities, organelle pathology and response to corticosteroids in patients with non-responsive coeliac disease. Clin Sci Mol Med 1978; 55: 293-306.

"Elmes M, Golden MK, Love AHS. Unresponsive coeliac disease. $Q J$ Med 1976; 69: 696-7.

'Love AHG, Elmes M, Golden MK, McMaster D. Zinc deficiency and coeliac disease. In: McNicholl, B McCarthy CF, Fottrell PF, eds. Perspectives in coeliac disease. Lancaster: MTP Press, 1978: 335-42.

'Dunnil MS, Whitehead R. A method for the quantitation of small intestinal biopsy specimens. J Clin Pathol 1972; 25: 243-6.

'Ferguson A, Murray D. Quantitation of intra-epithelial lymphocytes in human jejunum. Gut 1971; 12 : 988.

${ }^{8}$ Peters TJ, Batt RM, Heath JR, Tilleray J. The microassay of intestinal disaccharidases. Biochem Med 1976; 15: $145-8$.

'Evenson MA, Anderson CT. Ultramicro-analysis for copper, cadmium and zinc in human liver tissue by use of atomic absorption spectrophotometry and the heated graphite tube atomiser. Clin Chem 1975; 21 : 537-43.

${ }^{10}$ Vallee BL. Biochemistry, physiology and pathology of zinc. Physiol Rev 1959; 39: 443-90.

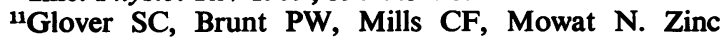
absorption and adult coeliac disease. Gut 1976; 17 : 813.
${ }^{12}$ Solomons NW, Rosenberg IH, Sandstead HH. Zinc nutrition in celiac sprue. Am J Clin Nutr 1976; 29: 371-5.

${ }^{13}$ Prasad AS. Zinc metabolism Springfield, USA: Thomas, 1966.

${ }^{14}$ Vallee BL. Zinc biochemistry in the normal and neoplastic growth process. In: Schultz J, Ahmad F, eds. Cancer enzymology, Miami Winter Symposia, 12. New York: Academic Press 1976: 159-95.

${ }^{15}$ Suzuki I,Kushida H. Studies on mammalian glycosidases. V. Effects of metal ions upon acidic and neutral $\alpha$ glucosidases, $\beta$-galactosidases and $\alpha$-mannosidases in liver extracts of rabbits. $J$ Biochem 1973; 74: 627-9.

${ }^{16}$ Peters TJ. Analytical subcellular fractionation of jejunal biopsy specimens: methodology and characterization of the organelles in normal tissue. Clin Sci Mol Med 1976; 51: 557-74.

${ }^{17}$ Lisowski J, Rajkumar TV, Wolf DP, Stein EA. Evidence for tightly-bound zinc in leucine aminopeptidase from. pig kidney. Acta Biochim Pol 1970; 17 : 311-3.

${ }^{18}$ Warren L, Glick MC, Nass MK. Membranes of animal cells. I. Methods of isolation of the surface membranes. J Cell Physiol 1966; 68: 269-87.

${ }^{10}$ Truding R, Shelanski MP, Daniels MP, Morell P. Comparison of surface membranes isolated from cultured murine neuroblastoma cells in the differentiated or undifferentiated state. J Biol Chem 1974; 249: 3973-82. 